\title{
EVIDENCIA DE DISCRIMINACIÓN EN EL HABLA
}

\author{
Giselle Chang \\ Ximena del Río
}

\begin{abstract}
RESUMEN
En este artículo las autoras analizan mensajes contradictorios que muestran discriminación hacia grupos minoritarios en una muestra de estudiantes universitarios a quienes se aplicó un instrumento que pretende medir el uso y frecuencia de expresiones discriminatorias, la valoración de palabras por medio de una variante de la escala de diferencial semántico de Linkert y establecer el perfil de los encuestados.
\end{abstract}

\begin{abstract}
The authors analyze conflicting messages that show discrimination towards minority groups in a sample of university students. They were given an instrument to measure the use and frequency of discriminatory expressions and the evaluation of words by means of a variant of Linkert's semantic differential, as well as to establish the sample profile.
\end{abstract}

\section{Introducción}

Aunque entre estudiosos de la cultura y el lenguaje es evidente el hecho de la condición pluricultural y multilingüe de Costa Rica, en la realidad cotidiana de la mayoría de la población esto se ignora o no se reconoce conscientemente. Consideramos que existe un doble discurso, tanto a nivel oficial como a nivel de otros sectores de la sociedad, respecto de la discriminación y valoración negativa de grupos "minoritarios", al considerarse esta sociedad como tolerante y abierta hacia la diversidad, cuando en la realidad hay una gran brecha entre discurso y práctica.

Es imposible no comunicarse; los seres humanos lo hacemos siempre y nuestra ideología se manifiesta hasta en los más ínfimos detalles. Las actitudes mostradas a través del lenguaje y otros comportamientos cotidianos ante diversas situaciones, son prácticas sociales significantes que reflejan la violencia de nuestra época ${ }^{1}$, mediante agresión física y sicológica. Estas prácticas obedecen a programaciones sociales que "condicionan el comportamiento humano en prácticamente todas las manifestaciones del quehacer cotidiano, y que ese ser 
humano no las percibe como tales sino hasta que, mediando frente al hecho exclama -iSí es evidente!" (Zeledón 1994: 68).

El interés en realizar este estudio se origina en la observación de mensajes contradictorios en todas las formas de comunicación, que se manifiestan en el lenguaje verbal, gestual, visual, según el interlocutor y la ocasión. Hay múltiples formas de acercarse a este doble discurso; nosotras pretendemos - mediante un estudio exploratorio- mostrar la existencia de prejuicios que evidencian en el habla la discriminación hacia los "otros", es decir, hacia aquellos que identificamos como diferentes.

El discurso revela comportamientos y actitudes manifiestas en nuestra sociedad, las cuales evidencian la existencia de prejuicios y discriminación hacia los otros. En la otredad se ubican tanto las minorías étnicas, como las minorías de campesinos y personas con edad, afiliación emotiva y sexual diferente. Aquellos culturalmente diferenciados devienen en objeto de menosprecio y burla en diferentes niveles.

Es conocida la falsa imagen que se proyecta a través de distintas instituciones ideológicas (escuela, iglesia, medios masivos y anuncios publicitarios, etc.) de que en Costa Rica no hay prejuicios ni discriminación. La misma Constitución de la República estipula que todos somos iguales ante la ley. Sin embargo, continuamente observamos hechos que demuestran lo contrario: persecución laboral y desempleo, acoso sexual, violencia física y psicológica contra grupos diferentes. En suma, nos movemos entre lo pasivo-agresivo, unas veces sancionando y otras veces celebrando las mismas actitudes y comportamientos.

En el caso específico que nos ocupa: la lengua, es evidente la presencia de estereoti$\operatorname{pos}^{2}$ acerca de otros grupos sociales, presentes en las creencias populares, prejuicios sociales y en las ideologías políticas que actúan como factores modeladores de mentalidades. El estereotipo denota una hipersimplificación de una creencia, así como una generalización de la realidad; pretende cristalizar características inexistentes, con el riesgo-como lo señala Cersósimo- de transformarse en una especie de fuentes culturales de la situación y en factor psicológico relevante del comportamiento social. De estas propiedades del estereotipo, dice Krech, se valen los manipuladores de la cultura que se sirven de las actitudes, los valores y los modelos comunes de comportamiento para favorecer sus propios intereses (Krech, citado en Cersósimo 1978: 13).

Es lugar común decir que los valores y actitudes se adquieren desde la infancia, donde la familia, la iglesia, la escuela y los medios masivos de difusión juegan un papel fundamental en el proceso de socialización de los individuos. Como sabemos, estos agentes están enraizados en una sociedad económico-social concreta, por lo que su función no ha sido siempre concientizar acerca del respeto a la diversidad, sino más bien reforzar actitudes etno-sociocentristas.

Como lo señalan los colegas estudiosos de la Ley 4169, "Día del descubrimiento y de la raza", la mayor parte de los textos de historia que han circulado en América Latina desde el siglo pasado son portadores de valores que exaltan al conquistador y colonizador, por lo que hasta la reconstrucción del pasado o memoria colectiva sirvió para justificar esta marginalización (Hernández, Ibarra y Quesada 1994: 14). La contribución de los manuales escolares ha sido la de fomentar el racismo y coadyuvar a que los costarricenses se identifiquen unilateralmente con los componentes de su ser nacional. 


\section{El aporte de la sociolingüística}

La interacción entre dos aspectos de la conducta humana: el uso de la lengua y la organización social de la conducta, es el punto de que se ocupa la sociolingüística, lo cual incluye no sólo el uso lingüístico per se, sino también las mismas actitudes linguísticas y los comportamientos explícitos hacia la lengua y sus usuarios (Fishman 1988: 33).

Es un hecho que los individuos tienen diferentes códigos lingüísticos y esta " diversidad es de interés para la sociolinguíistica, pero sólo cuando se puede correlacionar con rasgos sociales que no son lingüísticos" (Haugen 1974: 82), es decir, interesan los códigos que emite un individuo y que lo identifican como miembro de un grupo determinado (familia, aldea, clase, nación) si difieren de los códigos caracterizadores de individuos pertenecientes a otro grupo social.

Para Haugen, el foco de la sociolinguústica incluye no sólo la covariación positiva del lenguaje con los grupos sociales, sino también la tendencia a la conformidad dentro de los grupos, o sea, el proceso de uniformización que se produce en toda comunidad lingüística ${ }^{3}$. Desde una perspectiva histórica de la comunidad linguística, el código se halla en una constante lucha entre diferenciación (cambio linguístico) y estandarización (aceptación de los cambios por toda la comunidad hablante).

En otras palabras, la sociolinguística se ocupa de la relación entre la lengua y el habla (langue y parole) y su tarea consiste en determinar el funcionamiento y crecimiento de los sociolectos ${ }^{4}$ los cuales no son homogénew. La estructura léxica refleja la organización social (Fishman 1988: 191) de las comunidades hablantes, donde la presencia o ausencia de un rasgo puede indicar énfasis o influencias en ciertas retículas particulares de interacción.

Es obvio que aprendemos el lenguaje en sociedad. Los seres humanos, cuando nacen, aprenden no una competencia ideal, sino que producen lenguaje de acuerdo con su origen social (Quesada 1990: 28), a lo que se agrega que el aprendizaje de la lengua es el aprendizaje de las relaciones sociales a las que se integrará el individuo y es, a la vez, el aprendizaje del papel que la programación social le asigne.

La producción lingüística conlleva variación. Esto implica transformaciones en los diferentes niveles (fonológico, morfosintáctico, semántico), debido a los condicionamientos históricos y al contexto de producción de los diferentes sectores de la sociedad.

Por lo tanto, concordamos con quienes señalan que no hay hablantes ideales, ya que la lengua no es uniforme, sino que "es producto de una actividad condicionada por la estructura social, lo que implica que las variantes sociales de la lengua impiden hablar de un código único" (Quesada 1990: 31).

\section{Metodología}

Inicialmente, teníamos interés en recopilar datos de diferentes grupos etarios para comprobar la presencia de expresiones de prejuicio en diferentes sectores, como producto de los primeros años de socialización. Sin embargo, debido al carácter exploratorio de este estudio, nos decidimos a tomar el grupo intermedio: jóvenes adolescentes que acababan de terminar su educación formal básica. Este grupo es de fácil acceso para la aplicación de técnicas de investigación y no requiere de un asesoramiento individualizado para la aplicación del 
instrumento. Además la población juvenil, como generación intermedia y próxima transmisora de actitudes y valores, resulta de interés para el objetivo del estudio.

Diseñamos un cuestionario con el fin de recopilar datos sobre:

1) Uso (situación e interlocutor) y frecuencia (a menudo, de vez en cuando, nunca) de seis expresiones con una carga negativa hacia el indio, el negro, el homosexual, la mujer, el viejo y el campesino. Estas expresiones son de uso extendido en diferentes sectores sociales y zonas geográficas del país.

2) Valoración de seis palabras (indio, negro, chino, mujer, viejo, polo) por medio de 15 pares de adjetivos calificativos. Se trata de una modificación de la escala de diferencial semántico propuesta por Linkert.

3) Perfil de los encuestados (institución de estudio y nivel que cursa, sexo, edad, lugar de crianza y de residencia, ocupación del encuestado y de sus padres).

Encuestamos a 296 estudiantes de primer ingreso en las dos principales universidades públicas: Universidad de Costa Rica (UCR) y Universidad Nacional (UNA), lo que corresponde a aproximadamente el $10 \%$ de la población que actualmente cursa los Estudios Generales ${ }^{5}$. La muestra se escogió entre grupos matutinos, vespertinos y nocturnos.

\section{Corpus de expresiones}

De este corpus de expresiones, como anteriormente lo indicamos, escogimos únicamente seis expresiones (indicadas con asterisco) para la aplicación del instrumento evaluativo.

\subsection{Grupos étnicos}

\subsubsection{Indígenas}

1. Andar como indio repartiendo chicha

2. ¡Qué se cree esta india!

3. $\quad ¡ N o$ seás tan india! (arisca)

4. Indito

5. Ser de raza india

6. Hablar dialecto

7. Cholo

8. Se le subió el indio (enojarse)

9. Se le salió el indio (polada)

10. Come como alentado y trabaja como indio

11. Fulano la tiene como un indio (pene pequeño)

12. Picha de indio (banano pequeño)

13. Encholarse (enojarse, embarcarse)

14. Indio comido, puesto al camino

15. ¡Y con malicia indígena! 
16. Hay más jefes que indios

17. En fila india

\subsubsection{Negros}

1.* ¡Qué!, ¿acaso soy negro?

2. Acaso soy fulano (nombre o apellido de persona negra conocida)

3. Trabajar como un negro

4. Ya que la hicimos negra, hagámosla trompuda

5. Negrito

6. Moreno

7. Hablar Meikatelyu (inglés criollo limonense)

8. Grone (negro al revés)

9. Negro chumeco (castellanización de la palabra inglesa jamaican 'jamaiquino')

10. Fulano la tiene como negro (pene grande)

11. Fulano es un negrero (es un explotador)

\subsubsection{Chinos}

1. Chino cochino

2. Chinito

3. ¡Así murió un chino! (expresión que se usa cuando alguien está agachado y el trasero queda en un primer plano. No sabemos el origen de esta expresión)

4. Hablar en chino ( hablar de modo ininteligible)

\subsubsection{Nacionalidades}

Nicaragüenses

1. ¡Tenía que ser nica! (expresión multiuso en casos negativos)

2. ¡Cholo, jodido!

\subsection{Género}

\subsubsection{Mujer}

1.* ¡Tenía que ser vieja! (usada especialmente por los conductores)

2. ¡Quién mete a una mujer en cosas de hombre!

3. ¡Parecés una vieja! (cuando un hombre no puede hacer algo bien)

4. La tercio (por "terciopelo", serpiente venenosa; se usa para referirse a la esposa o compañera) 
5. A fulano le canta la gallina (comentario machista cuando la mujer asume un aparente papel masculino en el hogar)

\subsubsection{Exaltación de lo masculino}

1. Con los pantalones bien puestos

2. Hacer algo con huevos (hacerlo bien y con ganas)

\subsubsection{Afinidad Sexual}

\subsubsection{Homosexuales}

1. Playo

2.* ¡Dejáte de playadas! (de tonteras, tomar algo en serio)

$3 . \quad$ Maricón

4. Vuelta y rosca (bisexual)

5. Fulano enciende la bombeta por los dos lados (bisexual)

6. Es ambidiestro (bisexual)

7. Ese patea con las dos (bisexual)

8. Hacerle a alguien una playada (traición)

9. ¡No seás tan playo!

10. Mariposón

11. Raro

12. Pájaro

13. Plátano

14. Culiolo

15. Culiolada

16. Quebrado (el que tiene ademanes “femeninos")

\subsubsection{Lesbianas}

1. ¡Qué buen tractor ese!

2. Tortillera

3. Marimacha

4. Machorra

\subsection{Personas ancianas}

1.* Está viviendo horas extra

2. Está robando oxígeno

3. Fulano ya no está para esos trotes

4. A ese doncito ya ni se le para 


\subsection{Clase social}

\subsubsection{Campesinado}

$\begin{array}{ll}\text { 1. } & \text { No seás maicero } \\ \text { 2. } & \text { Se le salió el máiz } \\ \text { 3.* } & \text { iQué polada! } \\ \text { 4. } & \text { Concho } \\ \text { 5. } & \text { Polo }\end{array}$

\subsection{Variedades del español}

\subsubsection{Nivel léxico}
1. Diferiencia (diferencia)
2. ¡Achará! (lástima, qué pena)
3. Maldecido (mal dicho)
4. Sólido (solo)
5. Tallador (brassier)
6. Cazadora (autobús)
7. Acuantá (hace un rato)
8. Chunche (cualquier objeto)
9. Cursear (defecar)

\subsubsection{Nivel morfológico}
1. Más pior (peor)
2. Más mejor (mejor)
3. Dentren (entren)
4. Cállensen, váyansen (cállense, váyanse)

\subsubsection{Nivel fonológico}

4.5.3.1. Terminaciones en $r$ fricativa (costarricense) vs. $r$ vibrante múltiple

$$
\text { pior (peor), amor }
$$

\subsubsection{Grupos consonánticos}

volka (vodka), pecsi (pepsi), picsa (pizza), concecto (concepto) 


\subsubsection{Sustitución de j porf}

los juimos (nos fuimos), juegos artificiales (fuegos)

\subsubsection{Tratamiento de vocales}

riu (río), Palmaris (Palmares), vilos rilos y nada dicilos (vernos, reírnos y nada decirnos)

\section{Resultados}

\subsection{Perfil general de la población}

No hay diferencias significativas en cuanto al sexo de los estudiantes, ya que el $51.5 \%$ son mujeres y el $48.5 \%$ son hombres. La mayoría de ellos son estudiantes $(78.5 \%)$ y los pocos que trabajan tienen ocupaciones técnicas en el sector servicios. Hay una concentración de jóvenes menores de 20 años (77.5\%). Respecto de la región de crianza, tenemos que casi las 3/4 partes $(70.75 \%$ ) provienen de la Gran Área Metropolitana y un 29.25\% de otras áreas del país, sobre todo de otras zonas del Valle Central, de Guanacaste, de Limón y del Pacífico Central.

Con respecto a la ocupación de los progenitores, encontramos que la gran mayoría de las madres se ocupa de labores domésticas propias del hogar (61.48\%), le siguen las profesionales $(17.56 \%)$ y el resto son técnicas, comerciantes y pensionadas. Entre los padres predominan los técnicos que trabajan en el sector servicios (31.08\%), siguen los profesionales (21.95\%) y los comerciantes $(14.52 \%)$. Son pocos los que se dedican a labores agrícolas $(7.43 \%)$.

\subsection{Uso y situación de algunas expresiones discriminatorias}

\section{¡No seás tan indio!}

Es de uso común entre los jóvenes de ambos sexos en los contextos "con amigos" (25\%), "con compañeros" (20.2\%); "con la familia" (18.2\%), en la frecuencia "de vez en cuando". Es muy reducido su uso "con profesores o jefes" (1.77\%).

\section{¡Acaso soy negro!}

La mayor frecuencia de uso es "de vez en cuando" con amigos (19.2\%), entre hombres y de un $20.60 \%$ entre las mujeres.

\section{¡Tenía que ser vieja!}

En interlocutores de ambos sexos no hay gran diferencia en el uso de esta expresión. La situación más común es "con amigos"(18\% de hombres y 15\% de mujeres).

\section{¿Dejáte de playadas!}

Es más usada por los hombres en el contexto "con amigos" y la frecuencia "a menudo" $(20.2 \%)$. Las mujeres la usan "de vez en cuando" en ese mismo contexto (17.9\%). En ambos 
sexos, su uso es poco común en los contextos "en la casa' (menos del 6\%) y "con profesores o jefes" (menos del 1\% entre mujeres y el 3\% entre los hombres).

\section{Está robando oxígeno}

No hay mucha diferencia en el uso de esta expresión, según el sexo del interlocutor. Predomina la frecuencia "de vez en cuando" en todos los contextos. Es más común "con amigos" (14.1\% de las mujeres y $16.5 \%$ de los hombres). El contexto "en la casa" se da en el $8.9 \%$ de las mujeres y el $5.5 \%$ de los hombres.

\section{¿Qué polada!}

En relación con las otras expresiones, esta es la de uso más frecuente en jóvenes de ambos sexos. Un promedio del $23.2 \%$ de las mujeres la usa en casi todos los contextos, excepto en el "con profesores o jefes" (6.2\%). Los hombres la usan en menor grado y más que todo en los contextos "con amigos" y "con compañeros" (20.7\% en cada contexto).

\subsection{Valoración de palabras}

\section{Indio}

Se destacan como características con puntaje más alto: pobre $(59.4 \%)$ y trabajador (48.6\%), esforzado (40.85\%) y hábil (40.5\%). Los calificativos más bajos son rico (3.3\%), inmoral $(5.7 \%)$ y exitoso $(6.4 \%)$.

Por parejas con el calificativo negativo-positivo, sí encontramos una gran diferencia. Más positivas en: trabajador, agradable, inteligente, bueno, esforzado, hábil, confiado, educado, decente. Más negativas en: feo, fracasado, ingenuo, desordenado, sucio, pobre.

\section{Negro}

Se destaca como trabajador (45.9\%) y malcriado (43.2\%). El calificativo con menos puntaje es rico $(7.1 \%)$.

Las parejas con más características positivas son: trabajador, agradable, inteligente, hábil, vivo, confiado. Las negativas: feo, sucio, pobre, inmoral, malo, desordenado.

\section{Chino}

Se destacan con puntaje más alto: inteligente $(61.8 \%)$, trabajador $(52.3 \%)$, exitoso $(50.3 \%)$, esforzado (47.6\%), hábil $(45.9 \%)$, vivo $(45.2 \%)$, feo $(42.5 \%)$ y rico $(41.5 \%)$. El puntaje más bajo aparece en inútil (3\%), fracasado (3.3\%) y echado $(3.7 \%)$.

Las parejas con valoración positiva son: trabajador, inteligente, educado, esforzado, exitoso, hábil, vivo, ordenado, rico, decente. Las parejas negativas son: feo, desconfiado, sucio, desagradable. La pareja malo (18\%)-bueno (19\%) no presenta diferencia significativa.

\section{Mujer}

Se destacan con el mayor puntaje: guapa (73.9\%), agradable (59.1\%), limpia (57.4\%), ordenada $(53.7 \%)$, decente $(52.7 \%)$, educada $(51.3 \%)$, inteligente y trabajadora $(50 \%)$; las más bajas son tonta $(2.3 \%)$ y desagradable $(2.7 \%)$. 
Todos los pares son positivos, excepto confiada (28\%)-desconfiada (26\%) en que no hay gran diferencia.

\section{Viejo}

Las características con más alto puntaje son: educado (44.5\%) y agradable (44.2\%); la más baja es tonto $(6.1 \%)$.

Las parejas más positivas son trabajador, agradable, inteligente, educado, bueno, esforzado, exitoso, ordenado, limpio, decente. Las más negativas son feo, ingenuo, desconfiado y las neutras: hábil-inútil, rico-pobre.

\section{Polo}

Las características de más alto puntaje son desagradable (47.9\%) y tonto (41.2\%); las más bajas: guapo y rico (3\%).

La gran mayoría de los pares fueron valorados negativamente, excepto los pares malo-bueno y confiado-desconfiado.

\section{Conclusiones}

\subsection{Sobre el contexto y frecuencia de uso de las expresiones}

La frecuencia "nunca" decidimos eliminarla de los gráficos, pues al procesar los datos encontramos ausencia. Consideramos - con base en nuestra observación directa y la experiencia adquirida en otros trabajos sociolinguísticos- que aunque en general el porcentaje de uso registrado es relativamente bajo (lo más alto es un $23 \%$ de los encuestados), los datos son un buen indicio acerca de la extensión del uso de estas expresiones. Es interesante destacar la semejanza de la frecuencia y contexto de uso entre jóvenes de ambos sexos, lo que podría indicar que el habla de la cultura juvenil es bastante homogénea. El contexto de uso más frecuente es donde hay relaciones de solidaridad de grupo, "con amigos" y "con compañeros", y el menos frecuente "con jefes o profesores".

El contexto "en la casa" juega un doble papel en la supuesta censura del "lenguaje inadecuado" y la promoción y validación de los patrones aceptable. La casa o la familia juegan un relevante papel socializador del individuo y son el agente transmisor de una visión de mundo que en general está cargada de actitudes discriminatorias, que reflejan los valores de la sociedad. El hecho de que la diferencia de uso entre este contexto y los que poseen un mayor grado de confianza sea relativamente semejante, al contrario de lo que sucede con el contexto "con jefes o profesores", puede ser un indicador de la aceptación del uso de estas expresiones de intolerancia, prejuicio e irrespeto. Sin embargo, el uso de las llamadas "malas palabras", por ejemplo, no presenta una situación contraria, donde no son del todo aceptables.

\subsection{Valoración de palabras}

La mujer, el viejo y el chino son los términos valorados con mayor cantidad de características positivas $(14,11$ y 11 respectivamente, de una lista de 15 pares de características 
sitivas y negativas). El indio se encuentra en un nivel intermedio ( 8 positivas y 7 negativas); el negro y el polo son los términos que resultaron calificados con más características negativas (9 y 14 , respectivamente).

Los porcentajes extremos (más altos y más bajos) en las palabras hacen referencia a cualidades de diferentes tipos.

En el término indio se valora la situación económica. Es calificado como el más pobre, lo que podría indicar una cierta conciencia respecto de su situación de marginalidad y la relación etnia-clase.

En negro se valora la cualidad de trabajador. Esta podría considerarse como un atributo moral o físico (su fortaleza y resistencia ante los trabajos pesados). El saber popular registra expresiones que parecen reconocer la situación de explotación a la que históricamente el negro ha sido sometido; trabaja como un negro, es un negrero. Paralelamente, el negro es visto como vago, estereotipo que se basa en la diferente lógica económica y en la distribución del tiempo, en oposición al consumismo urbano.

En el término chino se valora la inteligencia, cualidad que se supone natural, como si existiera un correlato entre este atributo y este conglomerado de etnias que se denomina "chino".

En el caso del término mujer, se encuentran los más altos porcentajes en comparación con el resto de términos valorados, tanto en las características físicas (guapa o bonita, agradable), así como en las que denotan refinamiento y cualidades morales (educada, ordenada, limpia y decente). Consideramos que esta valoración tan positiva de la mujer no es signo de elogio, sino que es una respuesta al estereotipo femenino imperante en la sociedad patriarcal (reproducido por las mismas mujeres), que contribuye a mantener la situación de subordinación que históricamente ha recaído sobre ellas.

Para el término viejo, las apreciaciones en general revisten un carácter neutro. Se reconocen las cualidades adquiridas socialmente (educado, bueno, decente, inteligente, agradable), pero ninguna característica se asocia con la valoración de su experiencia.

$\mathrm{Al}$ término polo se le atribuyen cualidades que implican diferentes tipos de valoración, pero siempre con una carga negativa muy fuerte; de hecho, son los atributos más peyorativos de la lista de extremos (desagradable, fracasado, tonto). Polo originalmente hacía referencia al campesino. Hoy se usa para designar una gama de comportamientos (incluyendo lingüísticos) socialmente inaceptables, desde el punto de vista de la cultura oficial y que se relacionan con la vida campesina como sinónimo de atraso, mal gusto, mala educación, que se resumen en la errónea noción de "incultura". Consideramos que este tratamiento del término polo constituye una muestra de rechazo a las raíces campesinas de nuestra identidad cultural.

\section{Notas}

1. Aunque con esto no estamos afirmando que nuestra época sea más violenta que otras. La diferencia reside en la mayor difusión de la información y el efecto que esta tiene en la percepción que tengan los hablantes de otros grupos humanos. Al mismo tiempo que nos enteramos de las manifestaciones de violencia alrededor del mundo, hemos avanzado en la promoción y defensa de los derechos humanos.

2. Como lo señala Gaetano Cersósimo, "el estereotipo es una generalización anticientífica de la realidad, una imagen falsa del mundo socio-cultural (objetos, personas, colectividades, sociedades, relaciones, 
procesos, acontecimientos), pues se basa sobre una concepción inconsecuente con los hechos, subjetiva y afectiva" (Cersósimo 1978: 11).

3. Joshua Fishman (1988: 54) entiende por una comunidad linguística, aquella cuyos miembros participan por lo menos de una variedad linguística y de las normas para su uso adecuado.

4. El dialecto se refiere a variedades existentes dentro de una misma lengua. El idiolecto corresponde al habla particular, idiosincrática de un individuo; el sociolecto sería el código mínimo uniforme compartido por una comunidad de hablantes.

5. Curso integrado de Humanidades, que obligatoriamente deben seguir los estudiantes al inicio de su carrera en estos centros de estudio.

6. En un estudio realizado por las autoras en 1981, con una muestra de estudiantes de secundaria y de primer año de universidad, los encuestados manifestaron que en el contexto familiar nunca usaban términos como "hijueputa", "maje", "agüevado" o "tuanis".

\section{Bibliografía}

Cersósimo, Gaetano. 1978. Los estereotipos del costarricense. San José: Editorial Universidad de Costa Rica

Fishman, Joshua. 1988. Sociología del lenguaje. Madrid: Cátedra.

Haugen, Einar. 1974. "Algunos problemas en Sociolingüística”. En: Oscar Uribe Villegas (ed.).

Hernández, Ibarra, E. y Quesada. 1994. Discriminación y racismo en la historia costarricense. San José: Editorial Universidad de Costa Rica.

Quesada, Juan Diego. 1990. Pautas para el estudio, análisis y crítica de la sociolengua. Heredia: Editorial de la Universidad Nacional, EUNA.

Uribe Villegas, Oscar (ed.). 1974. La sociolingüística actual: algunos de sus problemas, planteamientos y soluciones. México: Universidad Nacional Autónoma de México.

Zeledón, Mario. 1994. Semiótica y vida cotidiana. San José: Editorial Alma Mater. 


\section{ANEXO 1 \\ Encuesta sobre expresiones del habla juvenil}

\section{Datos generales del informante}

1. Institución en que estudia

2. Nivel
5. Ocupación
6. Lugar de crianza (provincia, localidad o barrio)
7. Lugar de residencia_
8. Ocupación del padre_
9. Ocupación de la madre_

\section{Uso frecuencia interlocutor}

En cada cuadro o celda, encierre en un círculo el número correspondiente a la frecuencia (1, $2,3)$ y las personas con quien usted usa las siguientes expresiones (primera columna).
$1=$ a menudo
$2=$ de vez en cuando
$3=$ nunca

\begin{tabular}{|c|c|c|c|c|c|c|c|c|c|c|c|}
\hline $\begin{array}{c}\text { USO } \\
\text { FRECUENCIA }\end{array}$ & \multicolumn{3}{|c|}{ casa con familia } & \multicolumn{3}{|c|}{$\begin{array}{l}\text { con compañeros (as) } \\
\text { de trabajo o estudio }\end{array}$} & \multicolumn{2}{|c|}{$\begin{array}{l}\text { con amigos } \\
\mathrm{o} \text { amigas }\end{array}$} & \multicolumn{3}{|c|}{$\begin{array}{l}\text { con jefes o } \\
\text { profesores }\end{array}$} \\
\hline ¡No seás tan indio (a)! & 1 & 2 & 3 & 1 & 2 & 3 & 12 & & 1 & 2 & 3 \\
\hline ¡Qué! ¿Acaso soy negro(a)? & 1 & 2 & 3 & 1 & 2 & 3 & 12 & 3 & 1 & 2 & 3 \\
\hline ¡Tenía que ser una vieja! & 1 & 2 & 3 & 1 & 2 & 3 & 12 & 3 & 1 & 2 & 3 \\
\hline ¡Dejate de playadas! & 1 & 2 & 3 & 1 & 2 & 3 & 12 & 3 & 1 & 2 & 3 \\
\hline $\begin{array}{l}\text { XXX está viviendo horas extra } \\
\text { (o está robando oxígeno) }\end{array}$ & 1 & 2 & 3 & 1 & 2 & 3 & 12 & 3 & 1 & 2 & 3 \\
\hline ¡Qué polada! o ¡qué polo! & 1 & 2 & 3 & 1 & 2 & 3 & 12 & 3 & & 2 & 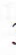 \\
\hline
\end{tabular}




\section{Valoración}

Para cada palabra, marque con una " $\mathrm{x}$ " las características que usted cree le corresponden

\begin{tabular}{|c|c|c|c|c|c|c|}
\hline Caracte & Indio & Negro & Chino & Mujer & Viejo & Polo \\
\hline \multicolumn{7}{|c|}{ trabajador (a) } \\
\hline \multicolumn{7}{|l|}{ vago (a) } \\
\hline \multicolumn{7}{|l|}{ feo (a) } \\
\hline \multicolumn{7}{|c|}{ guapo, bonita } \\
\hline \multicolumn{7}{|c|}{ agradable } \\
\hline \multicolumn{7}{|c|}{ desagradable } \\
\hline \multicolumn{7}{|c|}{ tonto (a) } \\
\hline \multicolumn{7}{|c|}{ inteligente } \\
\hline \multicolumn{7}{|c|}{ educado (a) } \\
\hline \multicolumn{7}{|c|}{ malcriado (a) } \\
\hline \multicolumn{7}{|c|}{ malo (a) } \\
\hline \multicolumn{7}{|c|}{ bueno (a) } \\
\hline \multicolumn{7}{|c|}{ esforzado (a) } \\
\hline \multicolumn{7}{|c|}{ echado (a) } \\
\hline \multicolumn{7}{|c|}{ exitoso (a) } \\
\hline \multicolumn{7}{|c|}{ fracasado (a) } \\
\hline \multicolumn{7}{|l|}{ hábil } \\
\hline \multicolumn{7}{|l|}{ inútil } \\
\hline \multicolumn{7}{|c|}{ vivo (a), astuto (a) } \\
\hline \multicolumn{7}{|c|}{ ingenuo (a), lento (a) } \\
\hline \multicolumn{7}{|c|}{ confiado (a) } \\
\hline \multicolumn{7}{|c|}{ desconfiado (a) } \\
\hline \multicolumn{7}{|c|}{ ordenado (a) } \\
\hline \multicolumn{7}{|c|}{ desordenado (a) } \\
\hline \multicolumn{7}{|c|}{ limpio (a) } \\
\hline \multicolumn{7}{|c|}{ sucio (a) } \\
\hline \multicolumn{7}{|l|}{ rico (a) } \\
\hline \multicolumn{7}{|l|}{ pobre } \\
\hline \multicolumn{7}{|l|}{ inmoral } \\
\hline decente & & & & & & \\
\hline
\end{tabular}



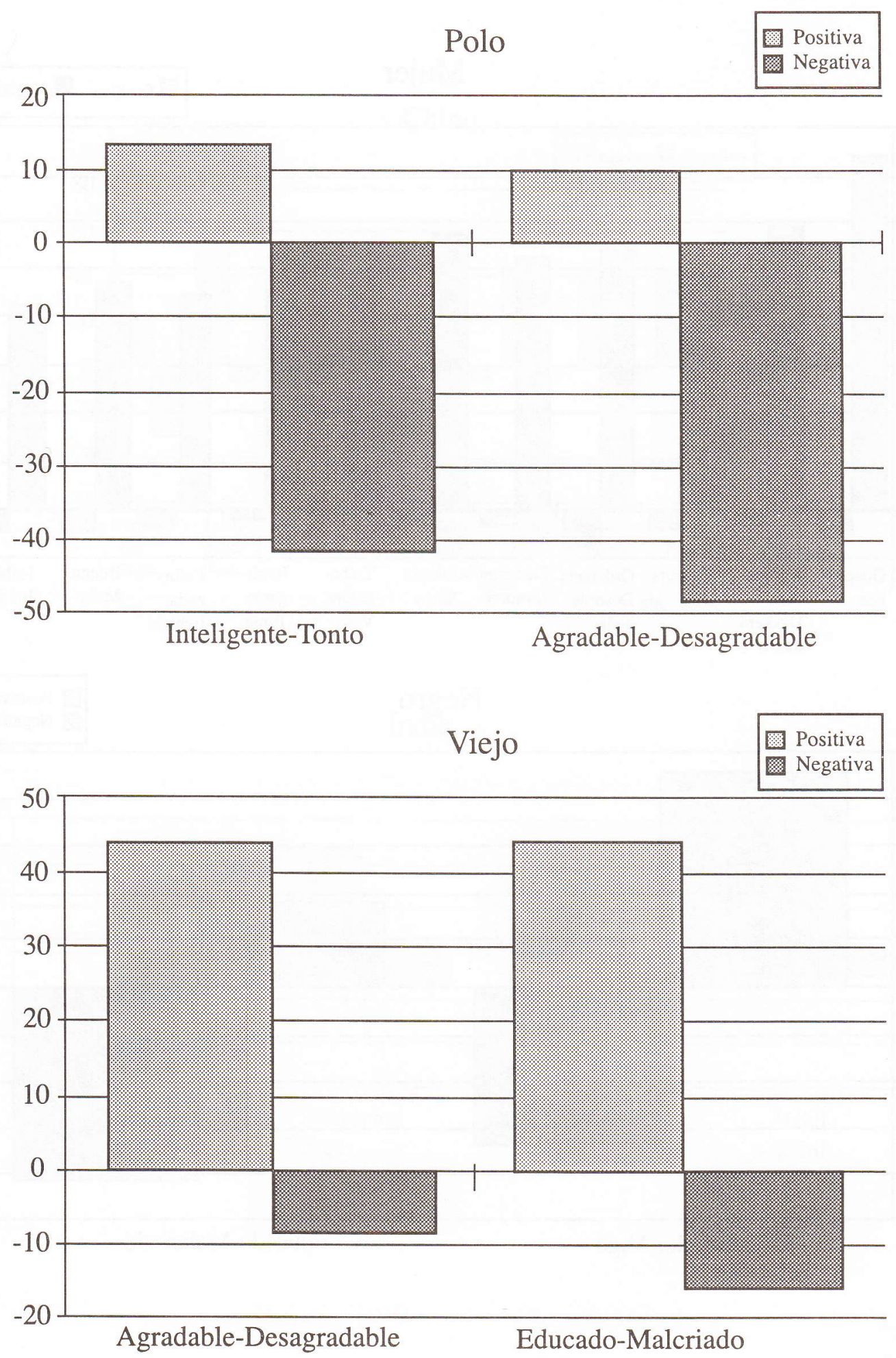


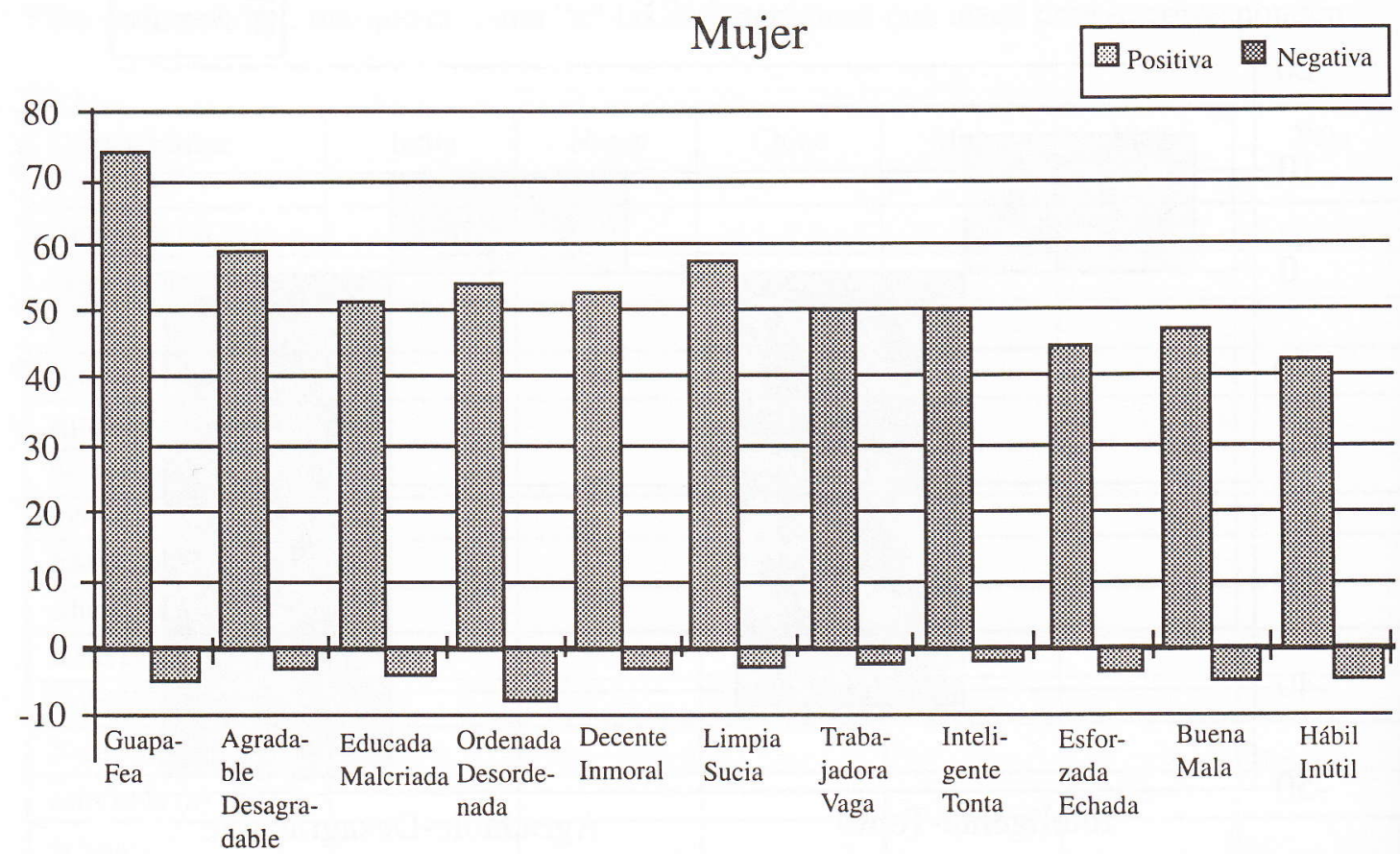

Negro

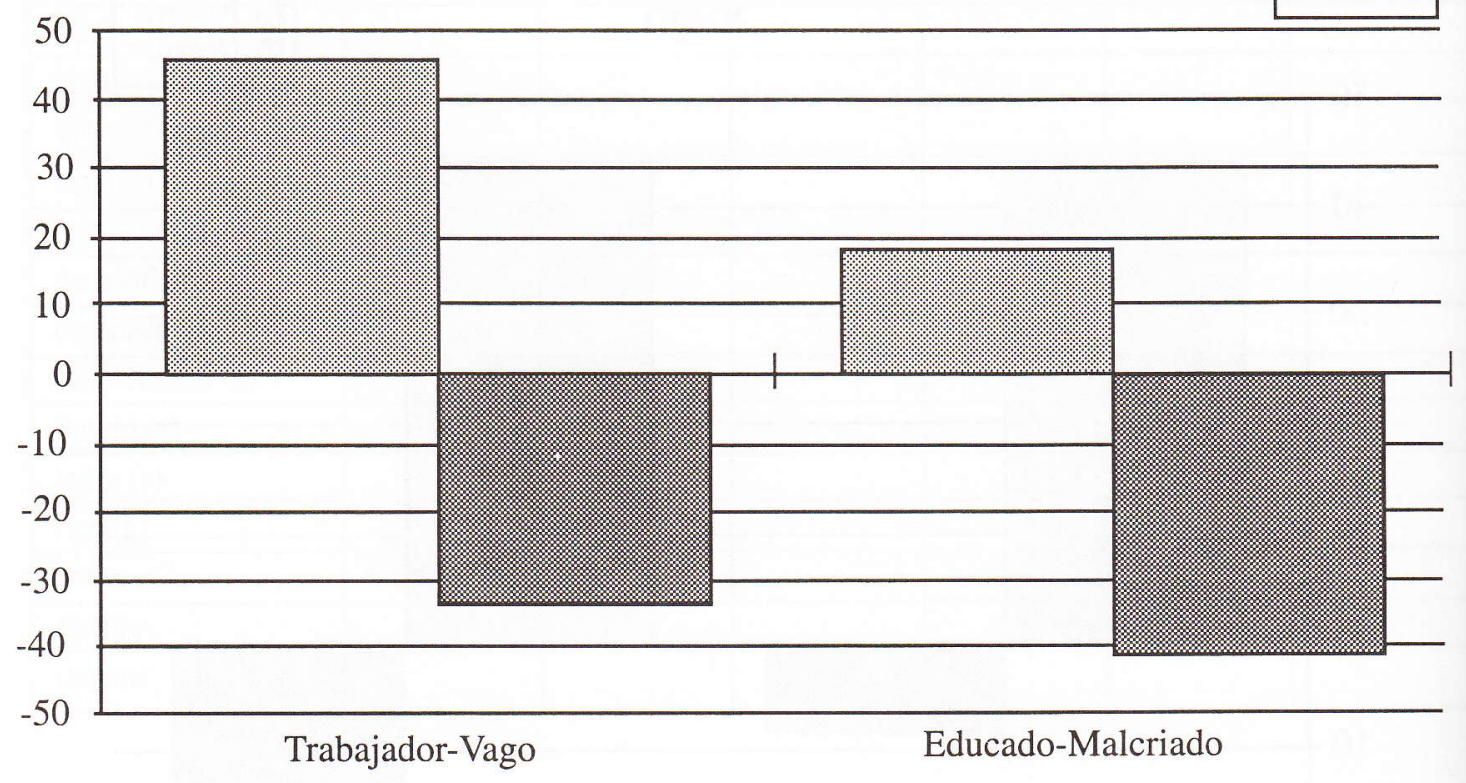




\section{Chino}

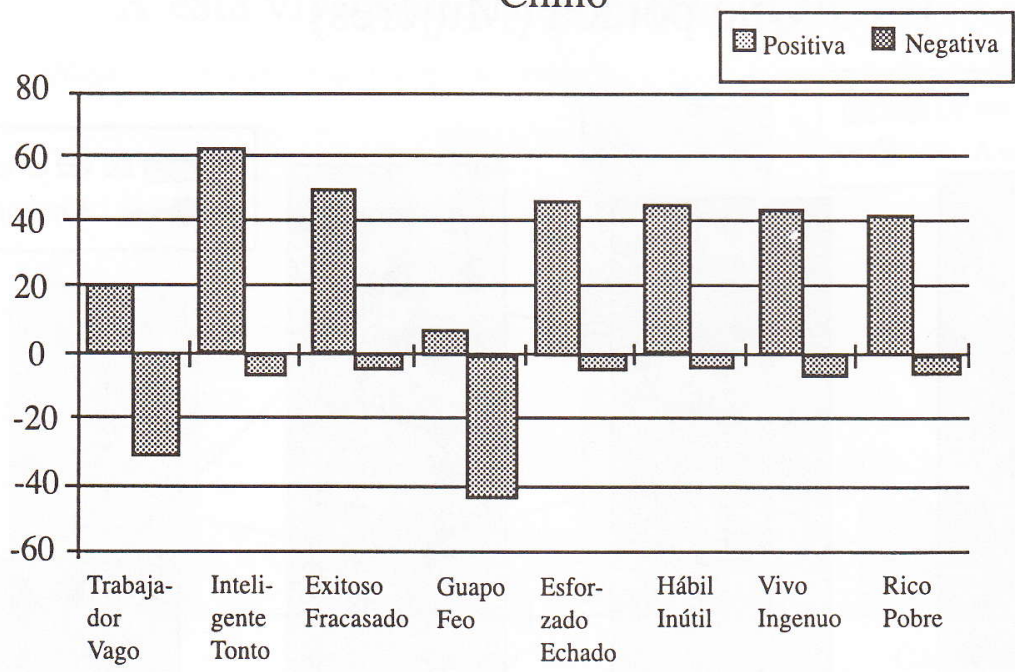

Indio

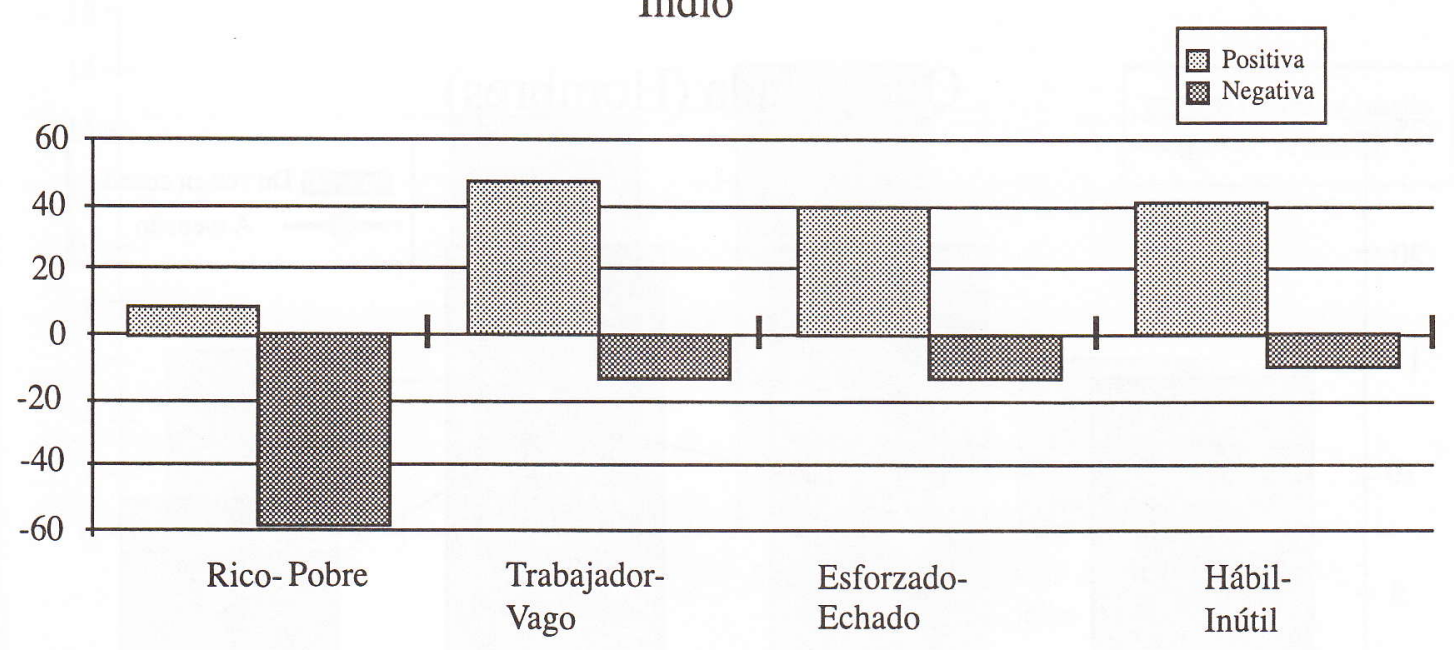




\section{Qué polada (Mujeres)}

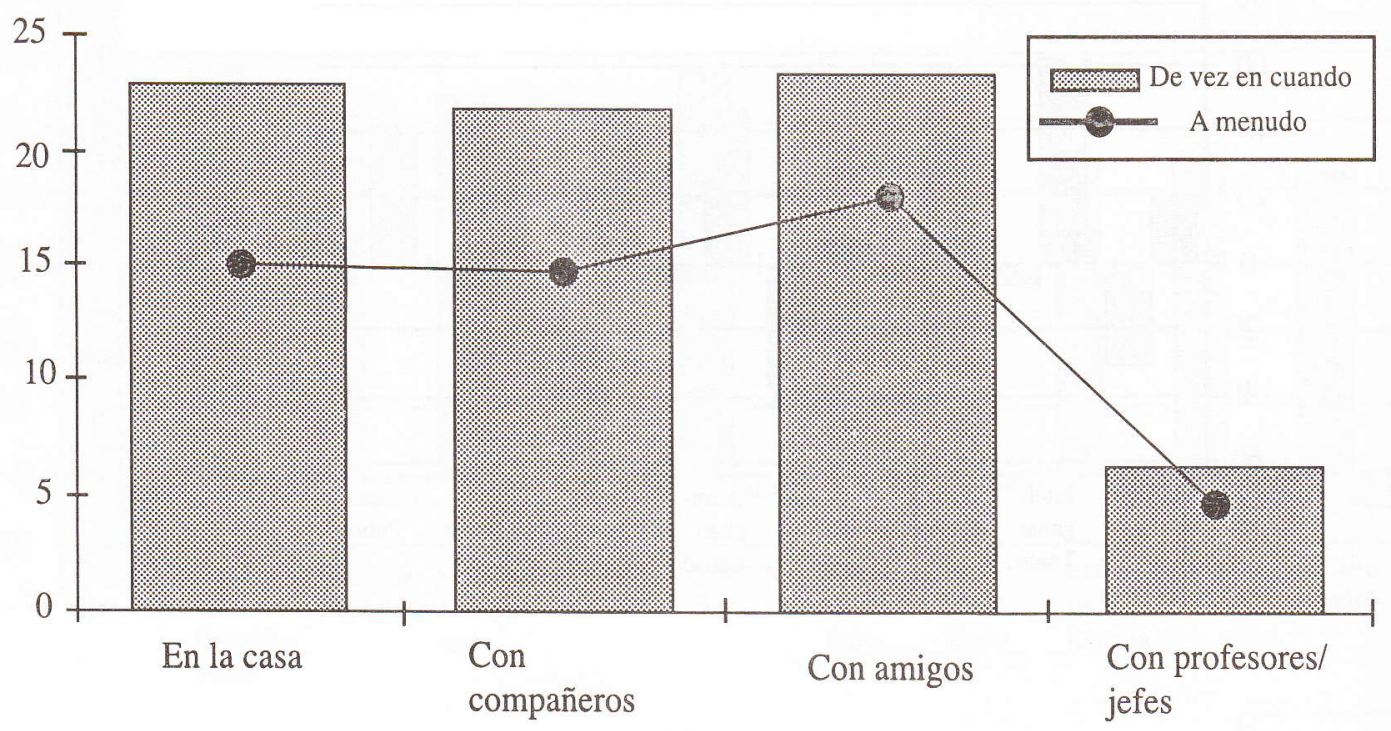

Qué polada (Hombres)

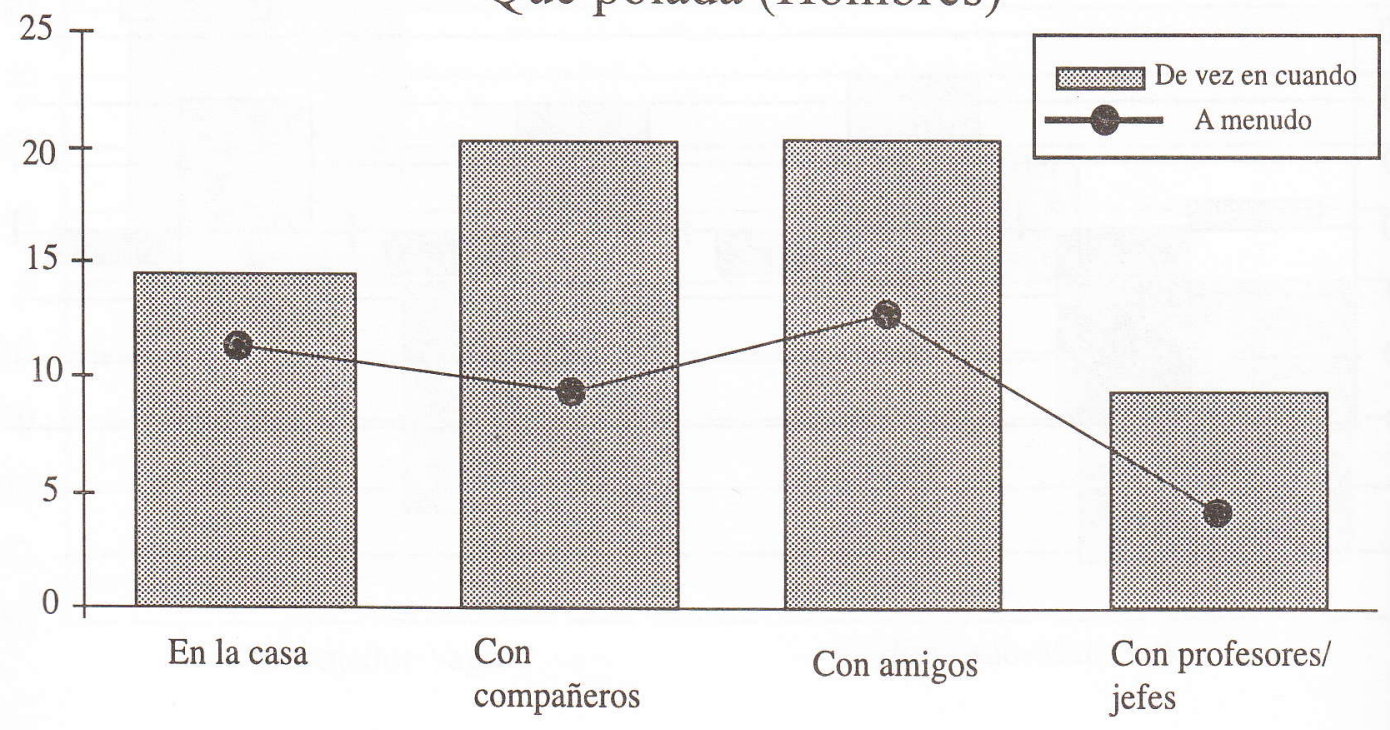




\section{X está viviendo horas extra (Mujeres)}

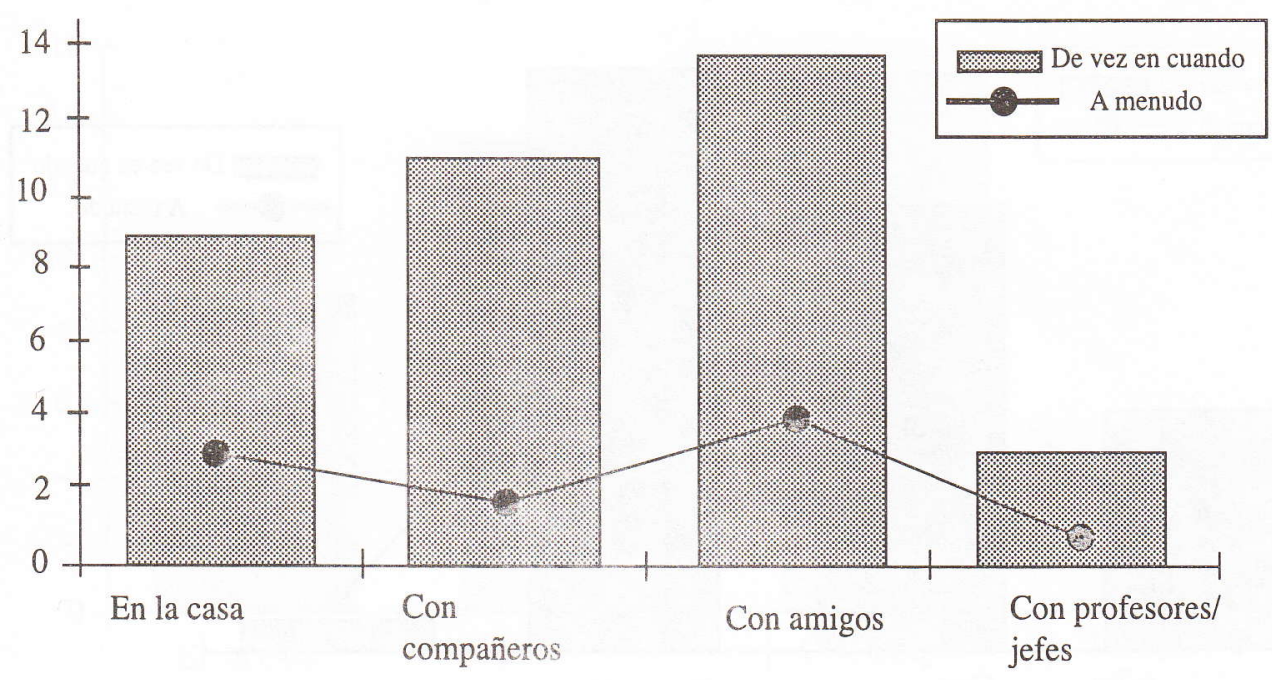

X está viviendo horas extra (Hombres)

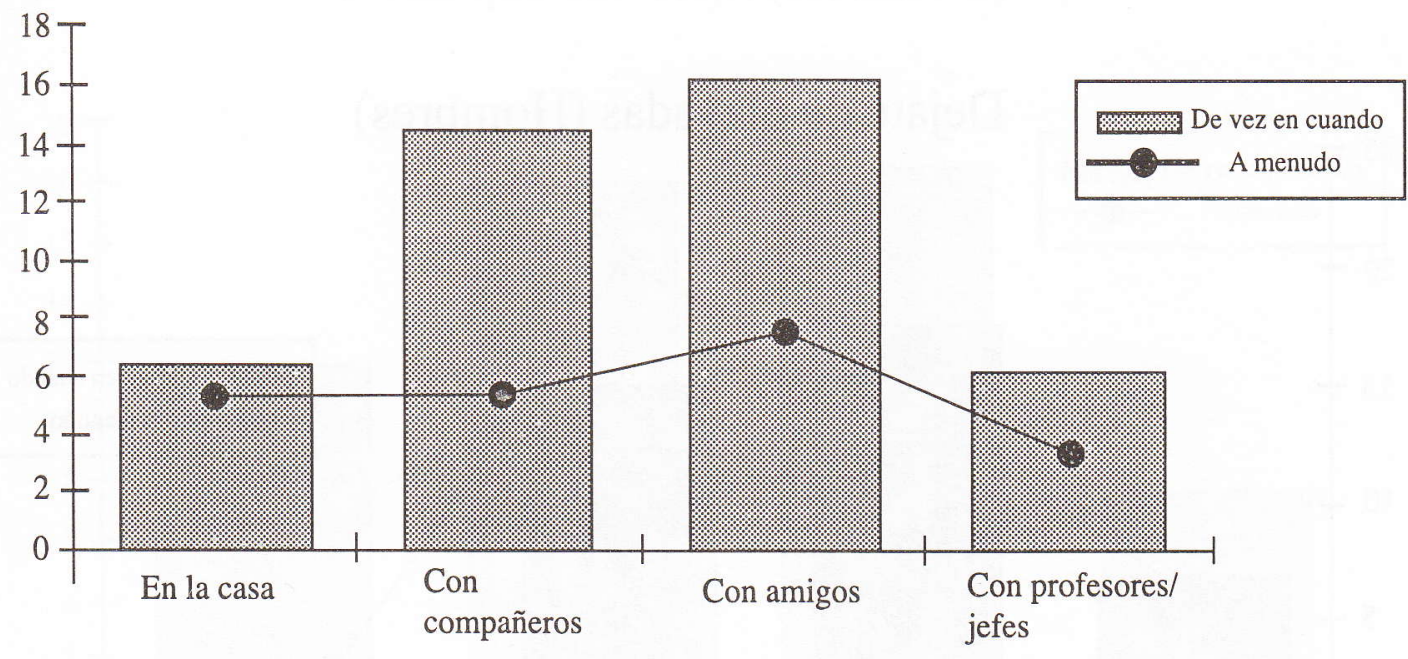




\section{Dejate de playadas (Mujeres)}

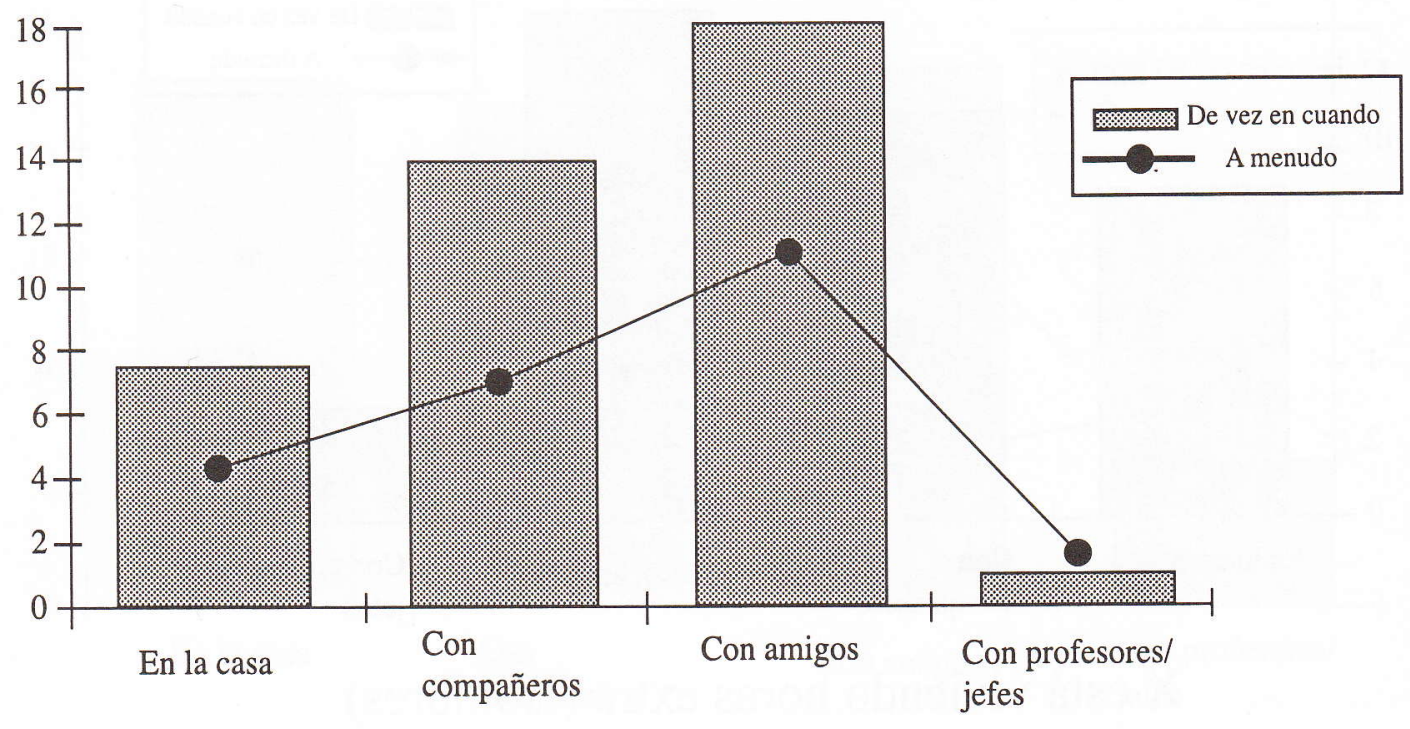

Dejate de playadas (Hombres)

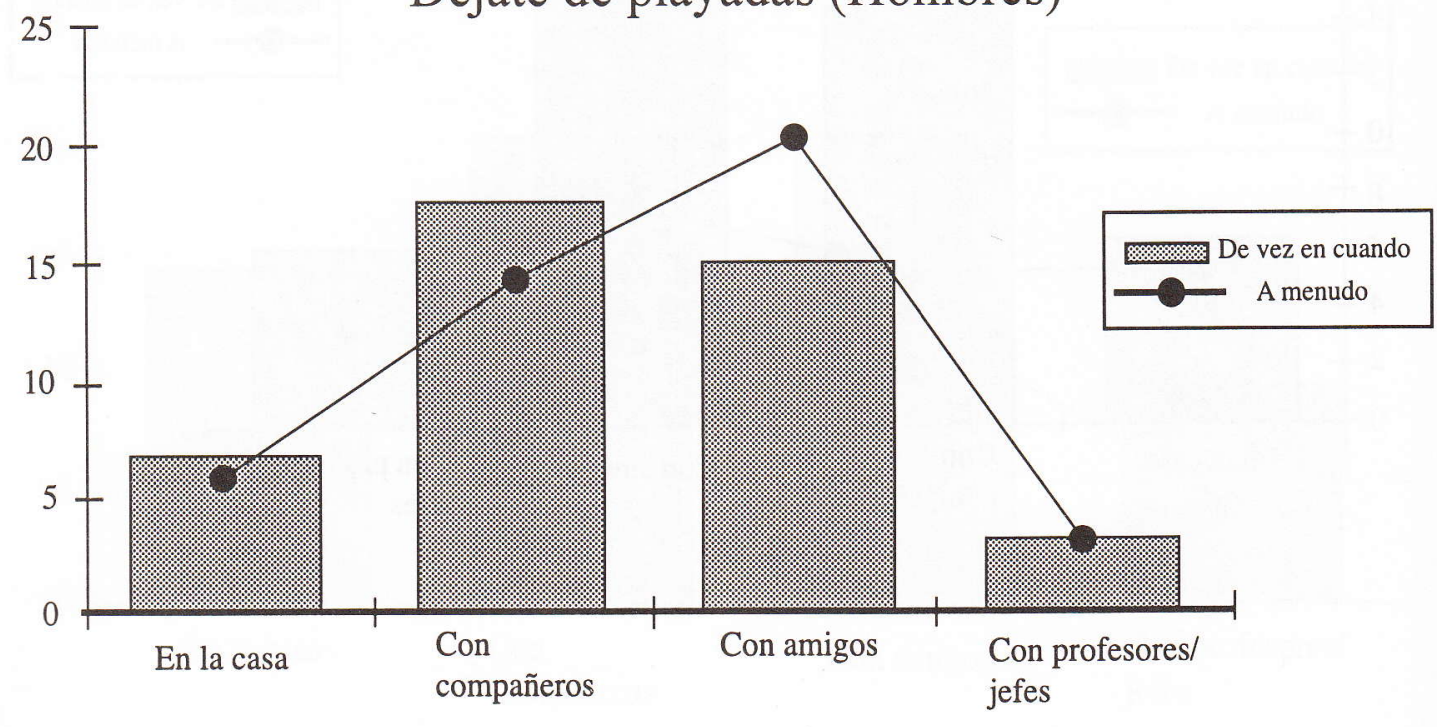




\section{Tenía que ser vieja (Mujeres)}

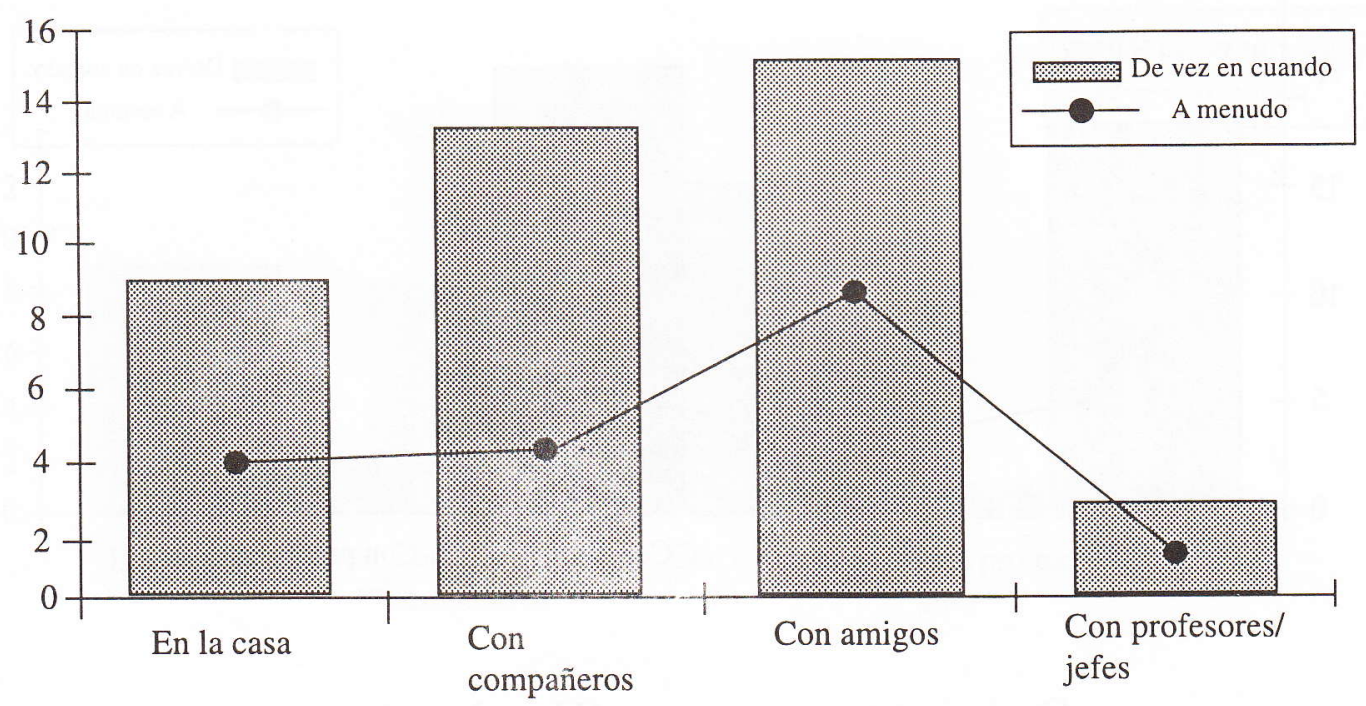

Tenía que ser vieja (Hombres)

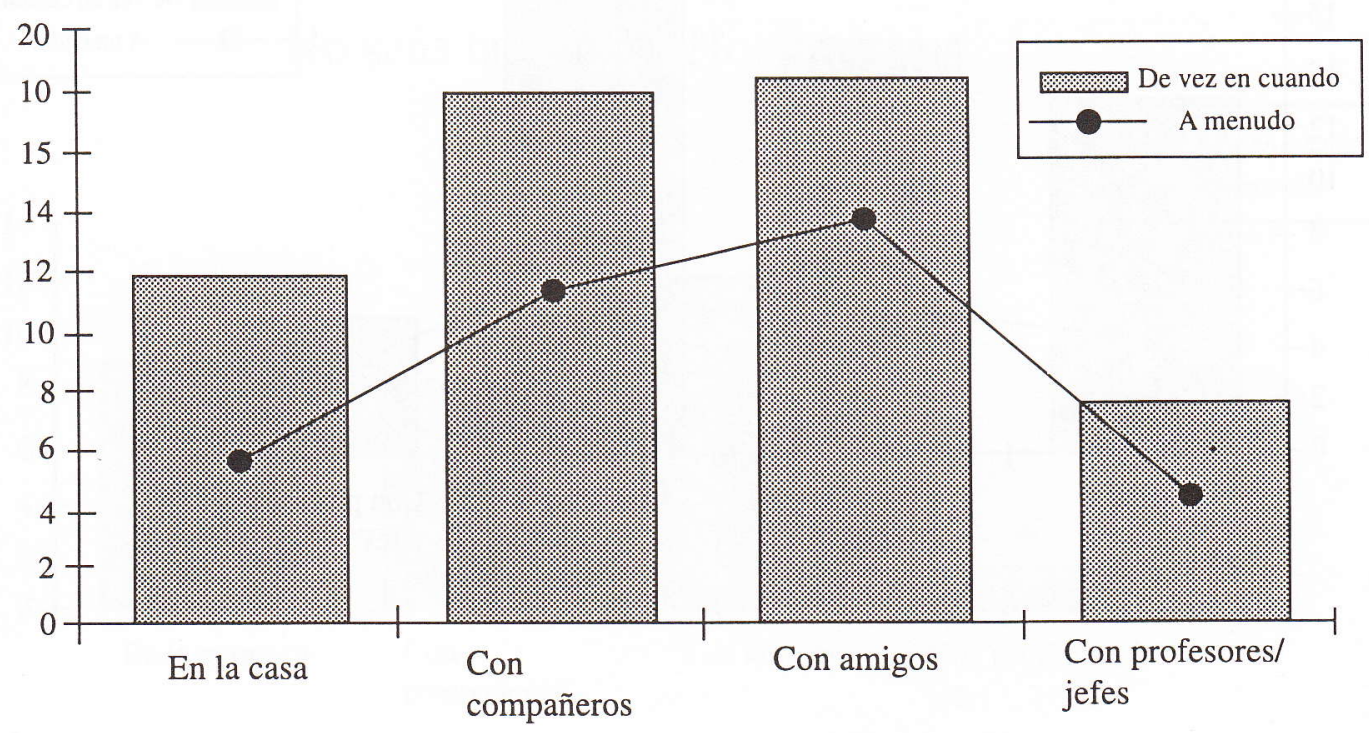




\section{Qué, acaso soy negro (Mujeres)}

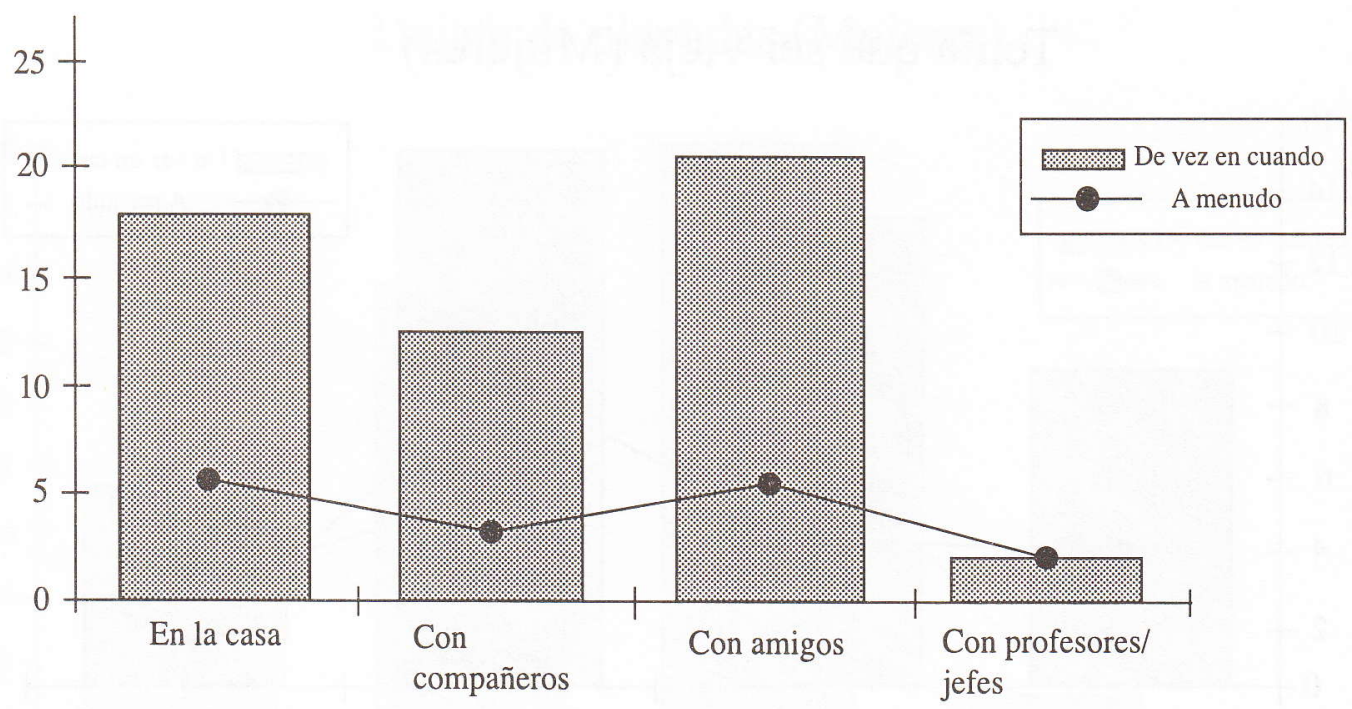

Qué, acaso soy negro (Hombres)

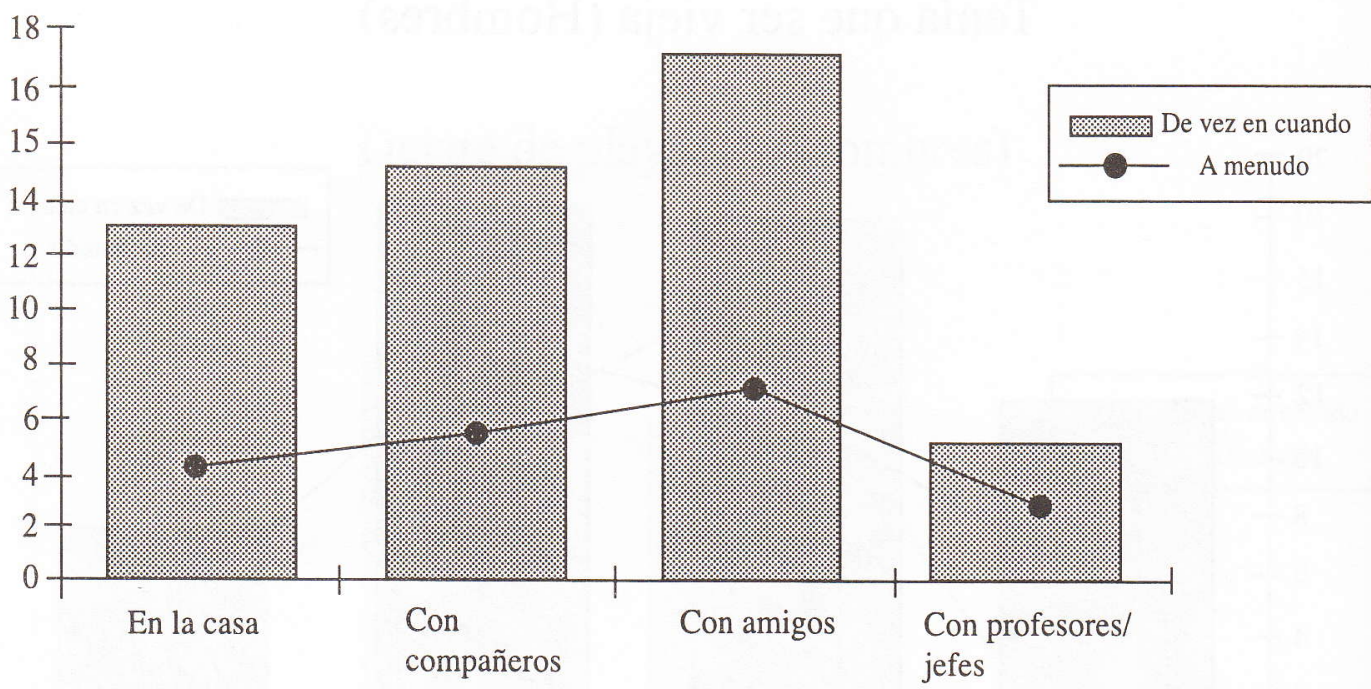




\section{No seás tan indio (Mujeres)}

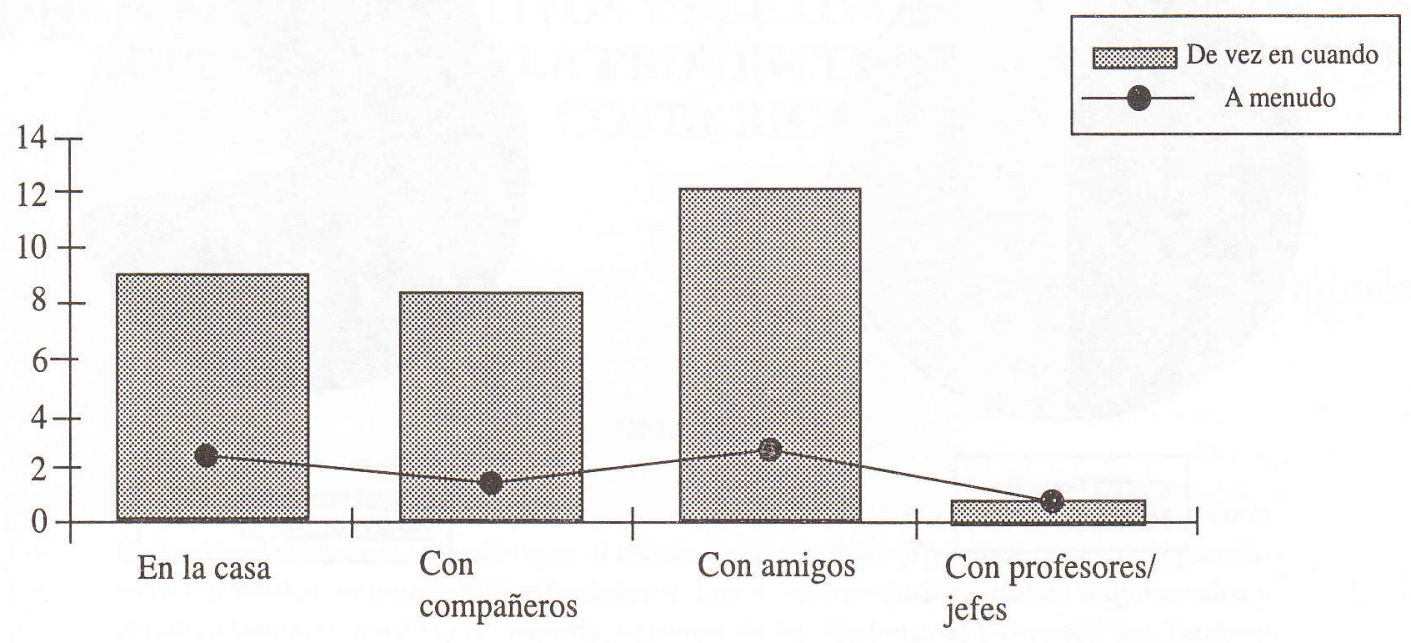

\section{No seás tan indio (Hombres)}

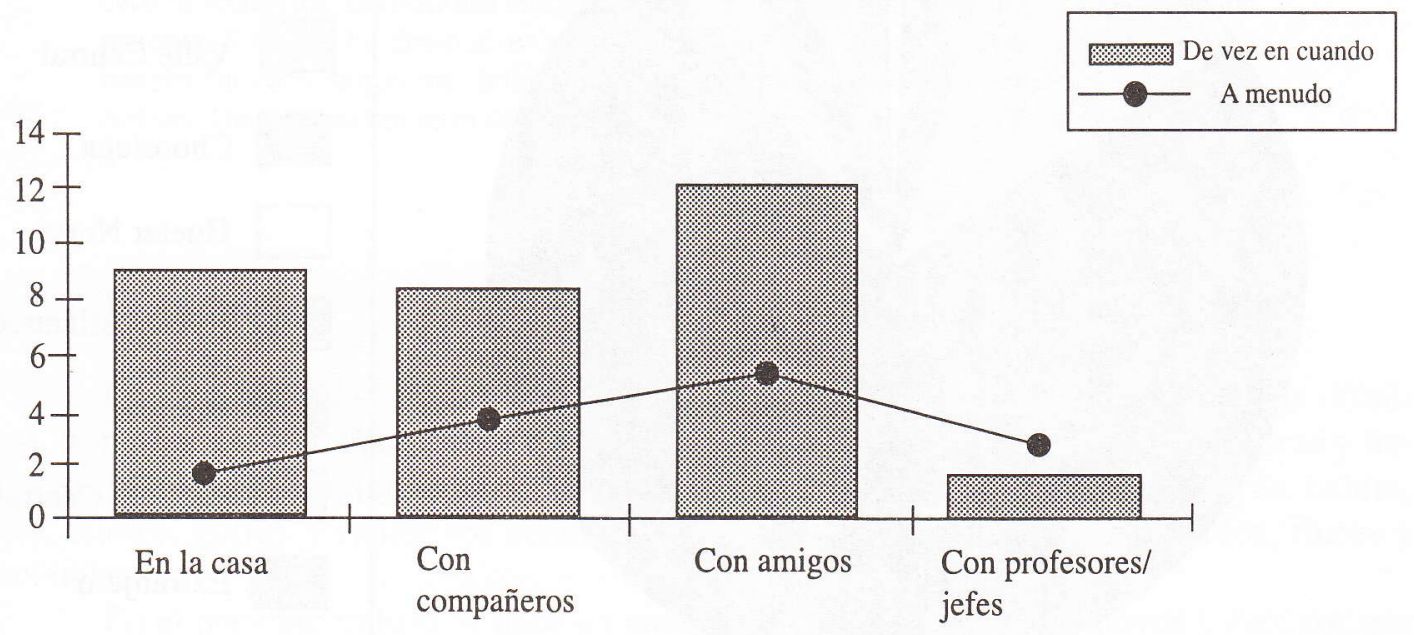



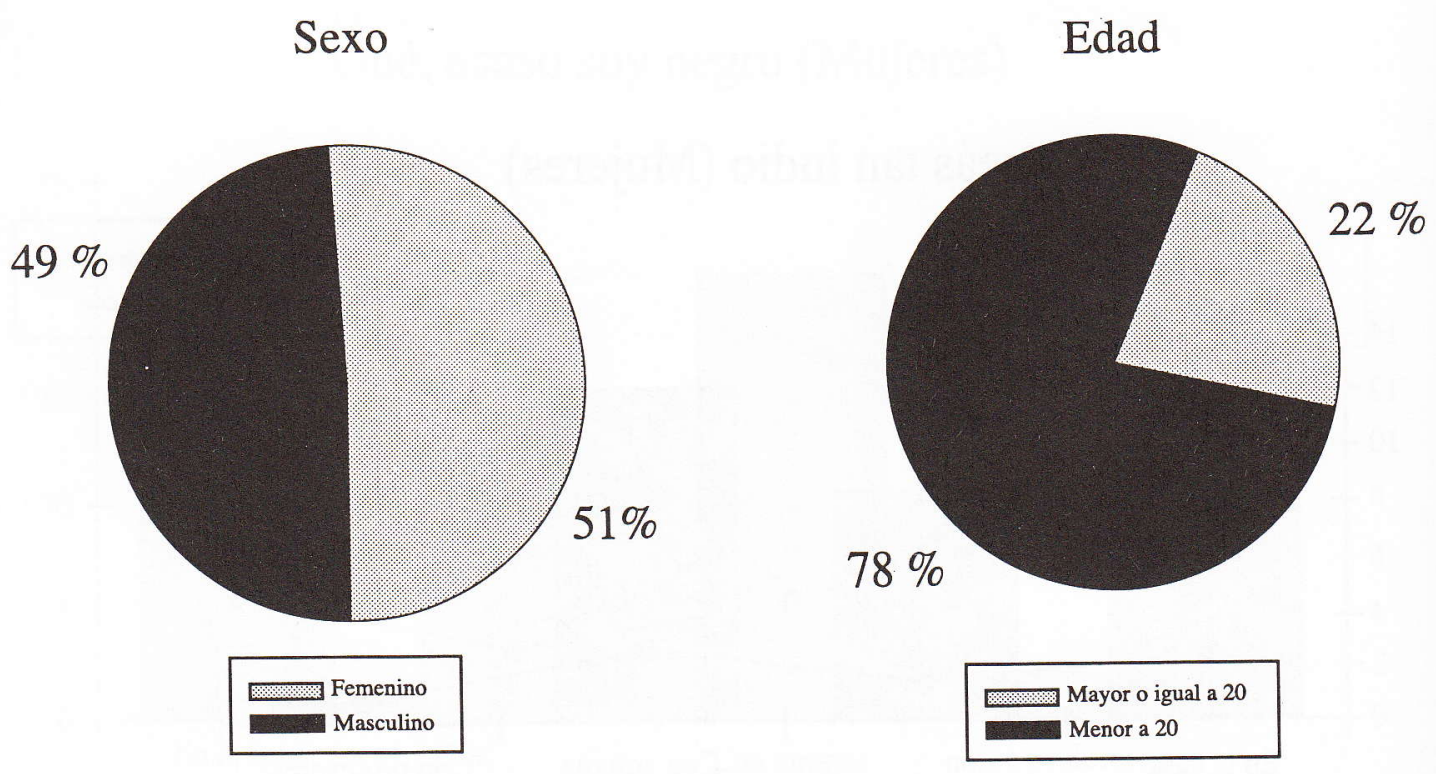

\section{Lugar de crianza}
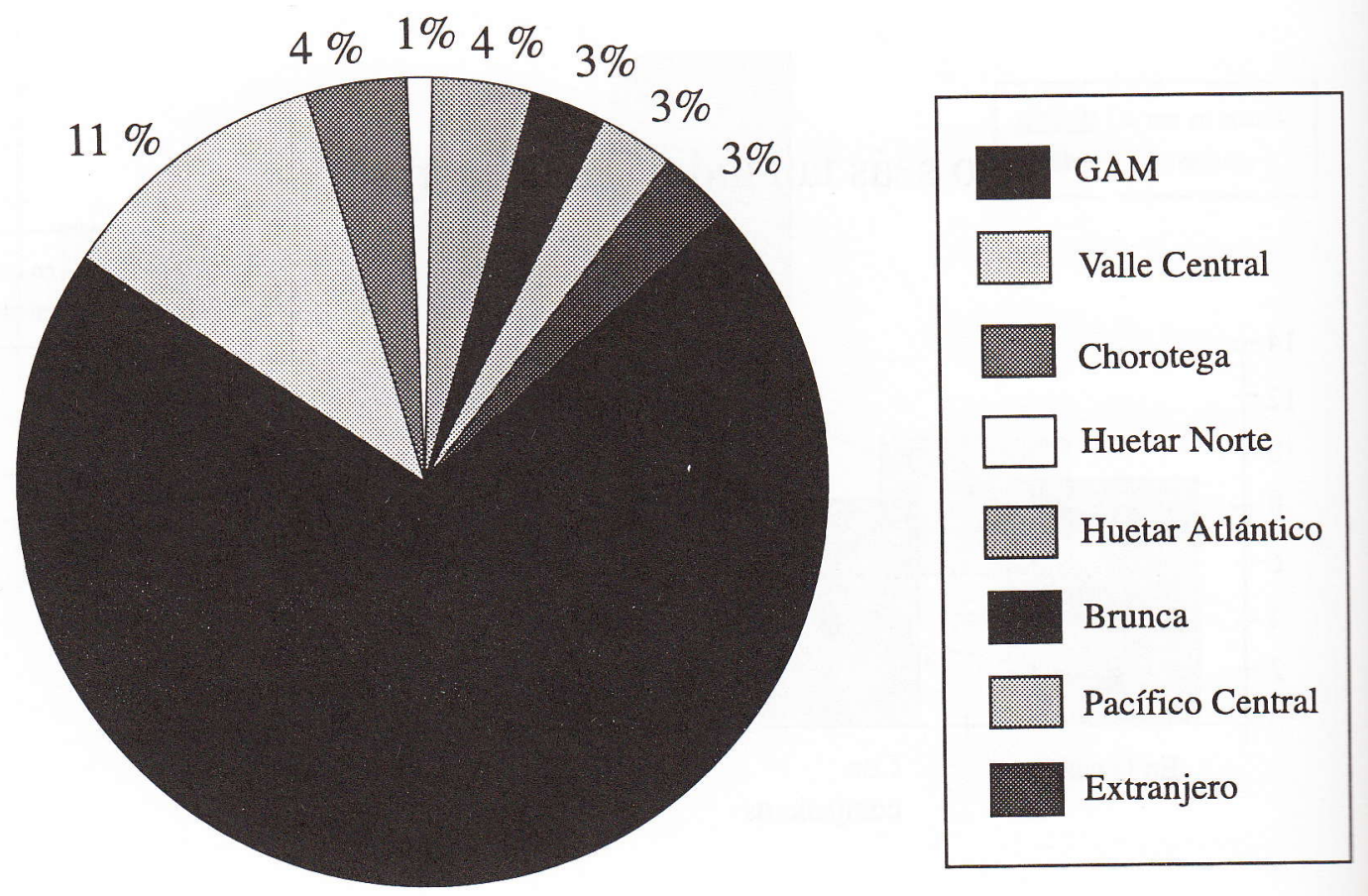

$71 \%$ 